\title{
Analysis of Investment Value of Listed Companies in New Energy Lithium Battery Industry Based on Factor Model
}

\author{
Ruohan Sun \\ School of Finance \\ Guizhou University of Finance and Economics \\ Guiyang, China \\ 347297047@qq.com
}

\begin{abstract}
As a clean, efficient and pollution-free new energy source, lithium batteries have entered various industries. The article is based on the macro environment background of the new energy lithium battery, the factor analysis method is used to calculate the 3 most representative financial indicators of the 18 lithium battery listed companies, which include the reduction of dimension, the correlation test and the comprehensive score, the reasonable and effective evaluation of the investment value of lithium battery industry and the future development trend are analyzed, and the feasibility of whether the investors and enterprises can enter the lithium battery industry is given.
\end{abstract}

Keywords-New energy industry; lithium battery; factor analysis; Quantitative investment

\section{INTRODUCTION}

As a clean energy source, lithium battery is an important part of the new energy industry and has become a hot spot in the development of clean energy economy. With the vigorous promotion of clean energy and low-carbon emissions vehicles, on the one hand, driven by the rapid development of the new energy electric vehicle industry downstream of the lithium battery industry, and on the other hand, the lithium battery industry has received continuous support from relevant government policies. Promote the rapid development of the lithium battery industry. At present, the production of lithium battery in the world is mainly in China, Korea and Japan. The market size of lithium battery industry in the three countries is about $95 \%$ of the global market. However, there is still a big gap between China and Japan and South Korea in the lithium battery equipment industry. There are small, scattered and disorderly characteristics in the structure, and the listed company shares of the industry. The investment strategy of the ticket is not obvious. ${ }^{[1]}$

As an important part of the new energy industry, the development of the lithium battery industry, on the one hand, will help to meet the investment and financing needs of China's lithium battery industry, on the other hand, it also brings new investment direction to the investors. As a new energy concept, the lithium battery industry, even in the early 2016, the meltdown stock market and the Shanghai Composite Index suffered a full-scale rise during the horizontal period in May. ${ }^{[2]}$ In addition, due to the current lack of regulation and maturity of China's securities market, the policy is weak. At the level, there is a high possibility of a large deviation between the investment value of the listed company and the price of the stock. Based on this, it is particularly important to evaluate the investment value of the lithium battery industry from the perspective of industry development and protection of investors to make a fair judgment.

\section{OVERVIEW OF THE DEVELOPMENT OF LITHIUM BATTERY INDUSTRY}

\section{A. Overview of the development of foreign lithium battery industry}

The birth of the first lithium battery began in 1958, but it was actually used in real life in the 1970s. With the continuous deepening of research on lithium batteries since 80s, lithium battery lithium batteries began to be widely used since 1994 . Now the production of lithium battery enterprises in China, Japan and South Korea has been the main production countries, meanwhile Japan and South Korea are more mature technology; the production of two lithium batteries in the current market occupies the main position.

\section{B. Development of lithium battery industry in China}

Lithium-ion battery industry in China was founded in the 80s of the last century. After the early reform and opening to the present several years, the lithium battery industry has become the largest lithium battery production country after Japan. Lithium battery has been widely used in domestic new energy vehicles, consumer digital electronic products, electric tools and other industries

The global lithium battery industry is mainly concentrated in China, Japan and South Korea. With the development of national economy and the progress of science and technology, China has become one of the largest lithium ion batteries in the world in 2015. The specific data are shown in Figure 1. 


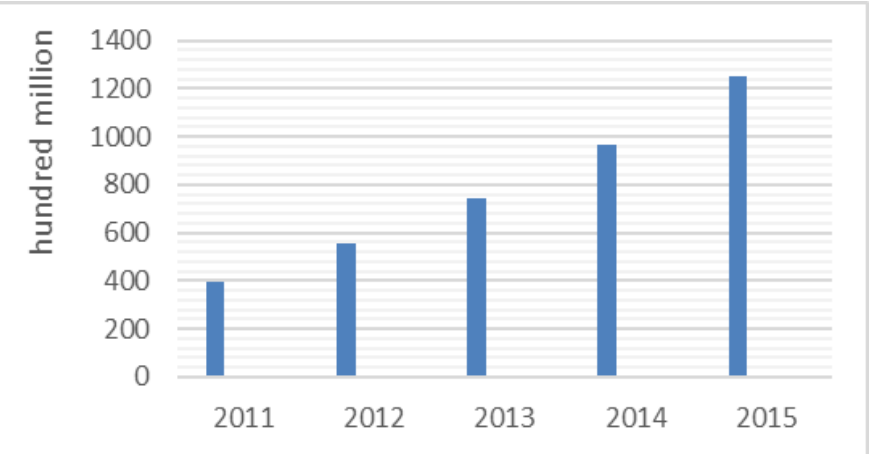

Fig. 1. The size of China's lithium battery market ( 2011-2015 )

\section{ANALYSIS ON THE CURRENT SITUATION OF CHINA'S LITHIUM BATTERY LISTED COMPANIES}

\section{A. Demand space for lithium batteries}

According to the data, China's lithium battery market has reached the highest level in the world in 2016. From the perspective of development trends, the emergence of electric vehicles in 2014 and the utilization of energy storage in 2015 have increased the market demand for lithium batteries, and the electric vehicle market has seen a surge. ${ }^{[3]}$

\section{B. Production analysis of the lithium battery industry}

According to relevant data survey, the sales of China's lithium battery industry in the past two years will exceed nearly 100 billion Yuan, an increase of one quarter compared with the initial stage of lithium batteries.

\section{ANALYSIS ON VALUE FACTOR OF STOCK INVESTMENT}

\section{A. sample selection}

The selection of sample data is the annual data of December 31, 2016, and 18 listed companies that produce lithium batteries have been selected in two securities markets in Shanghai and Shenzhen. See TABLE I for specific information.

TABLE I. BASIC INFORMATION OF LISTED COMPANIES IN LIT HIUM BATTERY INDUSTRY

\begin{tabular}{|c|c|c|c|c|}
\hline Code & Exchange & $\begin{array}{c}\text { Company } \\
\text { equity }\end{array}$ & $\begin{array}{c}\text { Total } \\
\text { market } \\
\text { value }\end{array}$ & $\begin{array}{c}\text { Business } \\
\text { income }\end{array}$ \\
\hline 000616 & SZSE & 143023.443 & 7465823.7 & $28,668.40$ \\
\hline 002077 & SZSE & 58034.851 & 10376631.41 & $136,959.00$ \\
\hline 300444 & SZSE & 28337.12 & 6800908.8 & $99,848.00$ \\
\hline 002057 & SZSE & 19938.167 & 3383506.94 & $34,494.40$ \\
\hline 002632 & SZSE & 59172.103 & 3383506.94 & $52,179.20$ \\
\hline 300116 & SZSE & 243252.456 & 22014347.3 & $446,730.00$ \\
\hline 600076 & SHSE & 103426.413 & 9711740.17 & $130,751.00$ \\
\hline 002085 & SZSE & 182239.973 & 36010618.7 & $948,573.00$ \\
\hline 600175 & SHSE & 357648.877 & 17703619.43 & $442,093.00$ \\
\hline 002759 & SZSE & 45217.998 & 11272846.98 & $49,888.30$ \\
\hline 603799 & SHSE & 59267.663 & 20844437.15 & $488,938.00$ \\
\hline 002074 & SZSE & 87760 & 27150094.55 & $475,793.00$ \\
\hline 601311 & SHSE & 84839.575 & 13854302.6 & $630,112.00$ \\
\hline 600549 & SHSE & 108157.4 & 23816259.48 & $852,839.00$ \\
\hline 300438 & SZSE & 28115.187 & 7938000 & $127,135.00$ \\
\hline 603026 & SHSE & 20268 & 8054503.2 & $379,092.00$ \\
\hline 002389 & SZSE & 70884.69 & 16360186.45 & $121,377.00$ \\
\hline 002460 & SZSE & 75269.553 & 19953958.39 & $284,412.00$ \\
\hline & & & & \\
\hline
\end{tabular}

\section{B. Indicator selection}

The following seven indicators are selected. Now, the following index code is used to express the name of the above index: X1 represents the total asset profit rate, X2 indicates the turnover rate of fixed assets, $\mathrm{X} 3$ indicates the turnover rate of accounts receivable, $\mathrm{X} 4$ indicates the ratio of net cash flow to liabilities, X5 table flow ratio, and X6 is the main business. The growth rate of revenue is $\mathrm{X} 7$, which represents the growth rate of net assets. ${ }^{[4]}$

\section{Empirical Study on stock investment value of Listed Companies in lithium battery industry based on factor model}

\section{1) principal component analysis}

After calculating by SPSS software, the p value of baret ball test is 0 , which indicates that the hypothesis that there is no correlation between the variables is not established, that is, the correlation between the selected variables is relatively strong.

\section{2) Factor analysis results}

From TABLE II, we can see that the common factor with a characteristic root greater than 1 is the first three. While the load matrix is rotated, it changes the cumulative contribution rate of the previous three common factors, but the cumulative contribution rate of the first three factors remains unchanged and the cumulative sum is still $81.314 \%$, and the first three factors are good, so the first three factors are good. It is used to explain the general level of investment value of listed companies of lithium battery.

TABLE II. TOT AL VARIANCE DECOMPOSITION T ABLE

\begin{tabular}{|c|c|c|c|}
\hline Component & \multicolumn{3}{|c|}{ Initial Eigenvalues } \\
& Total & Variance\% & Cumulative \% \\
\hline 1 & 2.727 & 38.960 & 38.960 \\
\hline 2 & 1.675 & 23.923 & 62.883 \\
\hline 3 & 1.290 & 18.431 & 81.314 \\
\hline 4 & .575 & 8.214 & 89.528 \\
\hline 5 & .468 & 6.686 & 96.214 \\
\hline 6 & .179 & 2.551 & 98.765 \\
\hline 7 & .086 & 1.235 & 100.000 \\
\hline
\end{tabular}

TABLE III. VARIABLE COVARIANCE

\begin{tabular}{ccc}
\hline & Initial & Extraction \\
\hline X1 & 1.000 & .724 \\
X2 & 1.000 & .790 \\
X3 & 1.000 & .738 \\
X4 & 1.000 & .897 \\
X5 & 1.000 & .802 \\
X6 & 1.000 & .915 \\
X7 & 1.000 & .826 \\
\hline
\end{tabular}

After extracting three common factors, the common degree of variables can also be obtained from subsequent calculations. The data of common variables are shown in TABLE III. The lowest commonality of variables is $72.4 \%$, which indicates that each factor has a relatively large interpretation of the variables, so it can be proved that the explanatory power of the selected three factors is more effective. ${ }^{[6]}$ 


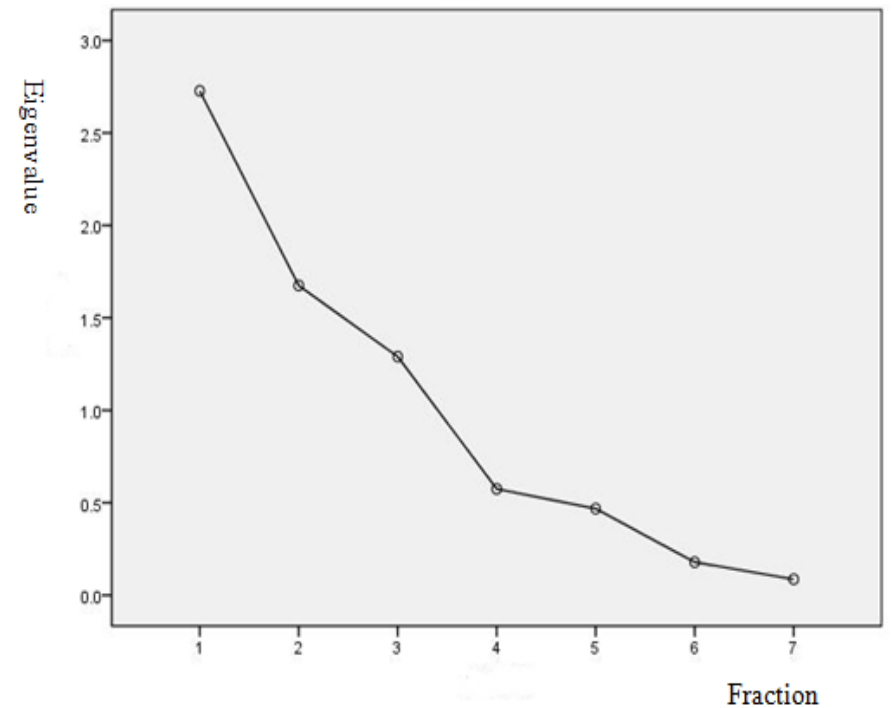

Fig. 2. Screen plot

As can be seen from Figure2, the trend of the first three factors is relatively steep, and the subsequent factors are relatively flat and the value of the eigenvalue is also less than 1 . According to this, it can be judged that the selection of the first three factors can explain the variables well. The total variance. According to the results of TABLE IV, the work of fitting seven variables using three common factors can be done by the following seven algebraic equations.

$$
\begin{aligned}
& Z X 1=0.949 F 1+0.073 F 2+0.089 F 3+\varepsilon 1 \\
& Z X 2=0.941 F 1-0.071 F 2-0.083 F 3+\varepsilon 2 \\
& Z X 3=0.861 F 1+0.264 F 2+0.123 F 3+\varepsilon 3 \\
& Z X 4=0.053 F 1+0.792 F 2+0.306 F 3+\varepsilon 4 \\
& Z X 5=0.293 F 1-0.725 F 2-0.355 F 3+\varepsilon 5 \\
& Z X 6=-0.038 F 1+0.384 F 2-0.801 F 3+\varepsilon 6 \\
& Z X 7=-0.329 F 1-0.542 F 2+0.632 F 3+\varepsilon 7
\end{aligned}
$$

Among these variables, variables are normalized variables. After factor analysis and dimensionality reduction, it can be concluded that only three factors can explain the factors that affect the investment value of the company.

TABLE IV. FACTOR LOAD MATRIX

\begin{tabular}{|c|c|c|c|}
\hline \multicolumn{5}{|c|}{} & Component \\
\hline & 1 & 2 & 3 \\
\hline $\mathrm{X} 1$ & .949 & .073 & -.089 \\
\hline $\mathrm{X} 2$ & .941 & .071 & -.083 \\
\hline $\mathrm{X} 3$ & .861 & .264 & .123 \\
\hline $\mathrm{X} 4$ & -.053 & -.792 & .306 \\
\hline $\mathrm{X} 5$ & -.293 & .725 & .355 \\
\hline $\mathrm{X} 6$ & -.038 & .384 & .801 \\
\hline $\mathrm{X} 7$ & -.329 & .542 & -.632 \\
\hline
\end{tabular}

As shown in TBALE V, the coefficient of load reflected by each common factor is separated to 0 or 1 after rotation.
TABLE V. THE FACTOR LOAD MATRIX AFTER ROT ATION

\begin{tabular}{cccc}
\hline & \multicolumn{3}{c}{ Component } \\
X1 & .947 & -.031 & 3 \\
X2 & .938 & -.035 & -.132 \\
X3 & .895 & .007 & -.128 \\
X4 & -.222 & .854 & .160 \\
X5 & -.199 & -.799 & .154 \\
X6 & .033 & -.169 & -.213 \\
X7 & -.155 & .404 & .872 \\
\hline
\end{tabular}

3) Empirical evaluation of stock investment value of Listed Companies in lithium battery industry

The article uses SPSS software to analyze the output function coefficient matrix, as shown in TABLE VI. According to TABLE VI factor score coefficient matrix, the seven selected financial indicators are used as variables to express the linear expression of three common factors. The score function of the three factors is as follows:

$$
\mathrm{F} 1=0.947 \mathrm{X} 1+0.938 \mathrm{X} 2+0.895 \mathrm{X} 3-0.222 \mathrm{X} 4
$$

$$
-0.199 \times 5+0.033 X 6-0.155 X 7
$$

$\mathrm{F} 2=-0.031 \mathrm{X} 1-0.035 \mathrm{X} 2+0.007 \mathrm{X} 3+0.854 \mathrm{X} 4$

$$
-0.799 \times 5-0.169 \times 6+0.404 \times 7
$$

F3 $=-0.132 X 1-0.128 X 2+0.160 \times 3=0.154 X 4$

$$
-0.213 \times 5+0.872 X 6+0.742 \times 7
$$

TABLE VI. FACTOR SCORE COEFFICIENT MATRIX

\begin{tabular}{|c|c|c|c|}
\hline \multicolumn{5}{|c|}{} & \multicolumn{2}{|c|}{ Component } \\
\hline & 1 & 2 & 3 \\
\hline $\mathrm{X} 1$ & -.107 & -.512 & -.085 \\
\hline $\mathrm{X} 2$ & .028 & -.187 & .634 \\
\hline $\mathrm{X} 3$ & -.026 & .194 & .486 \\
\hline $\mathrm{X} 4$ & .347 & .021 & -.065 \\
\hline $\mathrm{X} 5$ & -.058 & .565 & -.191 \\
\hline $\mathrm{X} 6$ & .350 & .024 & -.068 \\
\hline $\mathrm{X} 7$ & .339 & .021 & .134 \\
\hline
\end{tabular}

TABLE VII. EACH FACTOR SCORE TABLE

\begin{tabular}{|c|c|c|c|c|}
\hline Code & Exchange & FAC_1 & FAC_3 & FAC_3 \\
\hline 600175 & SZSE & -0.11373 & -0.46762 & 3.44339 \\
\hline 002077 & SZSE & -0.16745 & -0.00978 & -0.34338 \\
\hline 603799 & SZSE & -0.14888 & 0.17901 & 0.2443 \\
\hline 600549 & SZSE & -0.34209 & 0.009 & -0.19228 \\
\hline 002057 & SZSE & -0.3857 & 0.27108 & -0.79542 \\
\hline 603026 & SZSE & -0.05811 & -0.39818 & 1.21069 \\
\hline 002632 & SZSE & -0.13433 & 1.26824 & -0.92863 \\
\hline 002759 & SZSE & 0.66968 & 0.60924 & 0.14517 \\
\hline 002389 & SHSE & -0.31215 & 0.27146 & -0.72411 \\
\hline 300444 & SZSE & -0.3702 & -0.63547 & -0.17633 \\
\hline 300116 & SHSE & 3.81523 & -0.04713 & -0.28942 \\
\hline 002074 & SZSE & -0.28156 & -1.1258 & -0.57243 \\
\hline 601311 & SHSE & -0.67577 & -0.20677 & -0.25382 \\
\hline 002085 & SHSE & -0.31732 & -1.17412 & -0.27557 \\
\hline 300438 & SZSE & -0.49401 & -0.81908 & -0.42372 \\
\hline 600076 & SHSE & -0.44933 & -0.65909 & -0.62473 \\
\hline 002460 & SZSE & 0.2706 & -0.25826 & 0.03855 \\
\hline 000616 & SZSE & -0.50487 & 3.19327 & 0.51776 \\
\hline & & & & \\
\hline
\end{tabular}


Then calculate the score of three common factors, as shown in TABLE VII. According to the corresponding eigenvalues of each factor, the proportion of each factor in the overall variance contribution rate can be calculated. The concrete results are as follows:

$$
\begin{aligned}
\mathrm{F}= & \lambda 1 /(\lambda 1+\lambda 2+\lambda 3) \mathrm{F} 1+\lambda 2 /(\lambda 1+\lambda 2+\lambda 3) \mathrm{F} 2+\lambda 3 /(\lambda 1+\lambda 2+\lambda 3) \mathrm{F} 3 \\
& =0.479 \mathrm{~F} 1+0.294 \mathrm{~F} 2+0.227 \mathrm{~F} 3 \\
& \lambda 1=2.727, \quad \lambda 2=1.675, \quad \lambda 3=1.290 .
\end{aligned}
$$

SPSS software can be used to calculate the score of the composite factor we want.

Comp score $=0.479 *$ FAC_1+0.294*FAC_2+0.227* FAC_3.

TABLE VIII. COMPREHENSIVE SCORE TABLE

\begin{tabular}{|c|c|c|c|c|c|}
\hline Code & Exchange & $\begin{array}{c}\text { Comprehensive } \\
\text { score }\end{array}$ & $\begin{array}{c}\text { Score } \\
\text { ranking }\end{array}$ & PE ratio & $\begin{array}{c}\text { PE } \\
\text { ranking }\end{array}$ \\
\hline 600175 & SZSE & 4.27 & 1 & 109.544 & 12 \\
\hline 002077 & SZSE & -0.53 & 9 & 527.475 & 18 \\
\hline 603799 & SZSE & 0.288 & 6 & 358.734 & 17 \\
\hline 600549 & SZSE & -0.41 & 8 & 79.625 & 10 \\
\hline 002057 & SZSE & -1.14 & 16 & 98.707 & 11 \\
\hline 603026 & SZSE & 1.43 & 3 & 42.914 & 6 \\
\hline 002632 & SZSE & -0.95 & 13 & 140.757 & 15 \\
\hline 002759 & SZSE & 0.66 & 5 & 146.383 & 16 \\
\hline 002389 & SHSE & -1.02 & 15 & 115.679 & 13 \\
\hline 300444 & SZSE & -0.56 & 10 & 68.689 & 9 \\
\hline 300116 & SHSE & 1.44 & 2 & 51.378 & 7 \\
\hline 002074 & SZSE & 115.68 & 17 & 111.56 & 14 \\
\hline 601311 & SHSE & -0.70 & 11 & 25.460 & 3 \\
\hline 002085 & SHSE & -0.80 & 12 & 33.269 & 4 \\
\hline 300438 & SZSE & -0.99 & 14 & 57.736 & 8 \\
\hline 600076 & SHSE & -1.19 & 18 & 24.55 & 5 \\
\hline 002460 & SZSE & 0.12 & 7 & 42.873 & 5 \\
\hline 000616 & SZSE & 1.22 & 4 & -15.633 & 1 \\
\hline
\end{tabular}

Comp score is used to distinguish the intrinsic stock value of 18 lithium battery companies. From TABLE VIII, we can see that there is a certain difference in the ranking of the stock investment value of the listed companies of lithium battery industry and the ranking of the stock investment value of the listed lithium battery listed companies in the stock market. It shows that the stock of the 18 lithium battery listed companies is overvalued or underestimated.

\section{CONCLUSION}

Through the analysis of some representative financial indicators of 18 listed companies in the lithium battery industry, this paper finds that 600175, 300116, and 603026 are the most valuable investment values, so as to give investors an objective and reasonable investment proposal as far as possible. In China, because the development of the securities market is still in the stage of perfection, the current investors are mostly individual investors, lacking the corresponding investment expertise. As a new era, investors should pay more attention to the study of professional knowledge, improve their own analysis of the intrinsic value of the company and obtain successful investment, and rely on the sort within the portfolio to achieve the profit of the stock market.

\section{REFERENCES}

[1] Wang Ning. Broad prospects for lithium battery industry [J]. China nonferrous metals, 2015 (04): 1-2.

[2] Zhao Chuncheng. RESEARCH ON DEVELOPMENT FOR YK LITHIUM BATTERY EQUIPMENT MANUFACTURE COMPANY [D]. Guilin: Guangxi University, 2016.

[3] Li Fangfang, Zhang Xiaolong, Wu Yi, Li Yi Chen. Current Situation and Development Trend of Power Lithium Battery Industry [J]. traffic energy saving and environmental protection, 2016 (03): 14-16.

[4] Dong Feng Ming. China Lithium Battery Equipment Industry Analysis [J]. special equipment for electronic industry, 2016 (253): 6-11.

[5] Zhou Di, Yin Huayang, Lu Fang Kai, Zhang Zheng. SUPPLYDEMAND SITUATION AND FUTU R E DEVELOPMENT OF LITHIUM INDUSTRY[J]. resources and industry, 2016, 18 (04): 82-86.

[6] Chen Fei, Zhou Zhaoxiong. An Empirical Study on the Market of Lithium Battery[J]. technology and industry, 2017, 17 (01): 5-8. 